Supplement of Solid Earth, 11, 2169-2195, 2020

https://doi.org/10.5194/se-11-2169-2020-supplement

(C) Author(s) 2020. This work is distributed under

the Creative Commons Attribution 4.0 License.

(c) (i)

Supplement of

\title{
Structural control on fluid flow and shallow diagenesis: insights from calcite cementation along deformation bands in porous sandstones
}

Leonardo Del Sole et al.

Correspondence to: Leonardo Del Sole (leonardo.delsole@unibo.it)

The copyright of individual parts of the supplement might differ from the CC BY 4.0 License. 


\section{Supplementary Material}

\section{S1 Deformation band characteristics}

\section{Field and microstructural observations}

In Loiano, DBs occur along all the exposed sandstone sequence but display different patterns wherein the grain size,

5 sorting or porosity differ. In poorly sorted and/or low porosity coarse-grained sandstone, deformation appears more localized, and the trace of the DBs tends to be straight and develop along a single strand (Fig. 5e). In well-sorted and/or high porosity fine-grained sandstone, instead, deformation is more distributed and the trace of the DBs splits into several wavy and anastomosing segments (Fig. 5e). A clay smear occurs where DBs cut through thin, dark-colored clay levels (Fig. 5e).

Grains in the DBs are fractured and angular, whereas the host rock consists of more rounded and nearly undisturbed

10 medium- to coarse-grained sand grains (Figs. 9b-d and 10). However, some intragranular fractures are present at grain-tograin contacts (Fig. 10a-b). These microfractures are common in the boundary zone of the DBs (Fig. 10i). Microfractures in larger grains are often filled by fine-grained clasts. Detrital calcite clasts and bioclasts are often fractured or affected by pressure solution at contact points with other framework grains (Fig. 10b-d). Elongated detrital mica grains (mostly biotite) are bent between other grains and they tend to be preferentially aligned parallel to the bedding (Fig. 10c). In some cases,

15 where framework grains are in contact, they show straight-elongate planar to slightly undulated grain to grain contacts (Fig. $10 \mathrm{~b})$ that are also roughly parallel to the bedding. Locally, we observed partial dissolution of feldspar with formation of authigenic calcite (Fig. 10e). Minor calcite cement occurs also as syntaxial overgrowths around fossil shells and detrital carbonate grains (Fig. 10f).

Microstructural analysis in Bollène samples showed that a few intragranular fractures break framework grains at the 20 contact-point among two or more grains (Fig. 11a, b). These microfractures become more frequent approaching the DB (Fig. $11 \mathrm{~g}, \mathrm{~h}, \mathrm{j}$ ) and they are preferentially oriented with respect (ranging from ca. $30^{\circ}$ to $50^{\circ}$ ) to the force chain around DB (Fig. 8c). Despite the grains being fractured in the host rock sectors close to the DB, and the reduction in grain size is limited.

Feldspar sheared grains within the bands commonly organize in highly comminuted lenses. These stripes are well recognizable both in natural-light where they appear as brown lenses (Fig. 11g, h) and in CL where they show a bright light

25 blue color (Fig. 11h). The preferential alignment of elongated grains and stripes of detrital feldspar produce a foliated pattern that is sub-parallel to the DB.

\section{Discussion}

In both study areas, the key, common structural element are the DBs. In Loiano, geometric compatibility between DBs strike (Fig. 2d) and large-scale normal faults in this sector of the Northern Apennines (Fig. 2a, c; Antonellini and 30 Mollema, 2002; Picotti et al., 2009) indicates that they might be coeval. For instance, our study outcrops are close to a high- 
angle normal fault striking nearly N-S and dipping W (Del Sole et al., 2020). However, the presence of multiple sets of DBs, with different trends (Fig. 2d), kinematics, and ambiguous crosscutting relationships (Fig. 3) suggests that the Loiano Sandstones recorded multiple tectonic phases (Cibin et al., 2001; Antonellini and Mollema, 2002) from the Eocene onwards. A clear sequence of deformation events has not yet been defined. In Loiano, the inhomogeneous mesoscale pattern and 35 geometry of DBs along the exposed sandstone sequence is related to variations in host rock properties, such as sorting, porosity, and grain-size (Fig. 5e). Low porosity and/or poorly sorted coarse-grained host sandstones promote localized deformation commonly featured by a single straight-trace DB accommodating all displacement. High porosity and/or wellsorted fine-grained sandstones, instead, foster a more distributed deformation characterized by several anastomosing DB segments, where each segment accommodates part of the total displacement. Others host rock properties steering the overall

40 DB characteristics are mineralogy, lithification, and grain roundness (Antonellini and Mollema, 2002; Fossen et al., 2017; Del Sole and Antonellini, 2019).

In the Bollène quarry, structural features include diachronous and differently oriented DBs and occur only in the unconsolidated Turonian sands (Fig. 2c). Crosscutting relationships between different sets point out that ESE-WNW reverse DBs set should be the oldest. Their kinematics, low-angle planar attitude and organization in conjugate and densely

45 distributed networks, are typical features of DBs formed in a contractional regime. This evidence and the compatibility between the strike of reverse DBs and larger scale E-W trending thrusts and folds in the area (Fig. 2a, b) would indicate that they formed contemporaneously and within a single stress field (Ballas et al., 2013, 2014; Soliva et al., 2013). In particular, these DBs are likely associated with the Paleocene to early Oligocene Pyrenean shortening (Sanchis and Séranne, 2000; Lacombe and Jolivet, 2005) (Fig. 2a). The NE-SW/ENE-WSW strike-slip bands displace the ENE-WSW reverse DBs, the

50 NW-SE bands, and the NW-SE-trending carbonate cementation; hence, NE-SW/ENE-WSW strike-slip bands should be the younger set among the observed ones. They are most probably related to the (left-lateral) strike-slip reactivation of some major preexisting NE-SW faults in the region (e.g. Cevennes and Nîmes faults; Fig. 2a) during the Pyrenean event or in the Miocene to Quaternary age NNE-SSW Alpine contraction (Champion et al., 2000). The existence of a conjugate set of strike-slip bands with left-lateral (mostly ENE-WSW) and right-lateral (mostly NE-SW) kinematic (Fig. 6b) it places the

55 maximum-compressive stress axis $\left(\sigma_{1}\right)$ at ca. $\mathrm{N} 50^{\circ} \mathrm{E}$, thus, these DBs are consistent with the Miocene Alpine contraction (Fig. 2a). Two hypotheses can explain the occurrence of NW-SE/NNW-SSE DBs associated with cement nodules. They could have been formed as dextral strike-slip structures (Figs. 6b and 7f) during the NNE-SSW Pyrenean-Provencal shortening (Fig. 2a). Some of these faults could have been reactivated as normal faults during the NW-SE Oligocene-Early Miocene extension. A second possibility is related to the presence of a NE-SW map-scale normal fault, the Bollène Fault 60 (Saillet, 2009), close to the outcrops discussed in this study (Fig. 2c). In this framework, the NW-SE set of normal DBs could be genetically linked to a stress perturbation (in a dilation jog or quadrant) around the large-scale Bollène fault, during its Oligocene activity.

Microstructural observations indicate that DBs in both Loiano and Bollène, developed by mechanical grain fracturing and compaction with minor contributions by shear-related grain disaggregation by rolling and grain boundary 
65 sliding. Zone of bands show a similar pattern but the degree of cataclasis is higher than single DBs. These structures can be classified as compactive shear bands (CSB) with cataclasis (Aydin et al., 2006; Fossen et al., 2017).

\section{S2 Calcrete}

In the Bollène quarry, a massive hardened layer is exposed stratigraphically above the Turonian Sandstones, at roughly 3 meters above the quarry floor (Fig. S2a). This layer is characterized by a tabular structure and its lower boundary is

70 irregular, as well as its thickness (Fig. S2a, b). The features of this weathered crust and the invariably negative $\delta^{13} \mathrm{C}$ and $\delta^{18} \mathrm{O}$ values of its cement (Fig. 12b), suggest that it is a "massive" calcrete (e.g. Alonso-Zarza, 2003). The calcrete specimen was collected along this level (Fig. S2c, d), and the cement was sampled to compare its stable isotopes composition with that of cement in nodules (Fig. 12b).

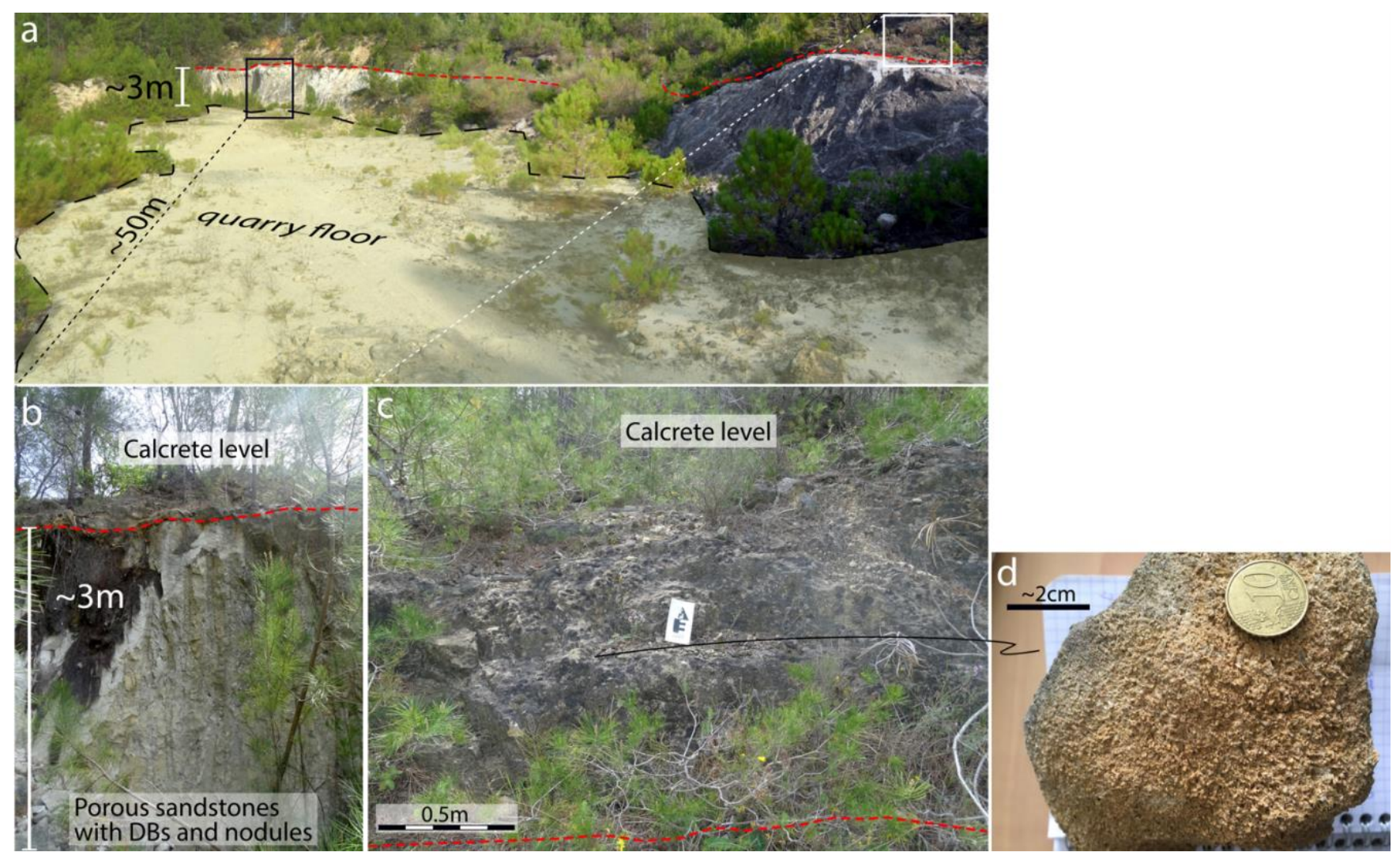

Figure S2.1 (a) Overview photograph that show the local stratigraphic framework of the Bollène quarry. The whitish Turonian sands, with DBs and nodules, are overlain by a reddish-brown massive calcrete level (b, c). (d) Calcrete hand specimen. 


\section{S3 Petrophysical data}

Table S3.1 Petrophysical data for the Loiano field site

(*) Kozeny-Carman (KC) permeability

\begin{tabular}{lccc}
\hline Parameters & & & Unit \\
\hline & HR & DB & - \\
Porosity & $2.24 \mathrm{E}-01$ & $4.50 \mathrm{E}-02$ & Darcy \\
Intrinsic permeability & $2.94 \mathrm{E}+00$ & $5.00 \mathrm{E}-03$ & $\mathrm{~K} / \mathrm{n}$ \\
Hydraulic conductivity & $9.60 \mathrm{E}+00$ & $8.11 \mathrm{E}-02$ & \\
\hline
\end{tabular}

85

(**) In situ air-permeability

\begin{tabular}{lccccccc}
\hline & Feature & Data N & Median & Mean & Std. Dev. & Min & Max \\
\hline & HR & 174 & 1053.46 & 2963.35 & 5409.98 & 0.29 & 39729.44 \\
Permeability (mD) & DB & 56 & 17.16 & 38.65 & 80.65 & 0.04 & 522.41 \\
& NOD & 118 & 5.76 & 31.70 & 56.49 & 0.03 & 339.65 \\
\hline
\end{tabular}

HR - host rock; NOD — nodule.

(*) Del Sole and Antonellini, (2019); (**) Del Sole et al., (2020).

90 Table S3.2 Petrophysical data for the Bollène field site (***)

\begin{tabular}{lcccc}
\hline Parameters & HR & DB & DB & \% \\
\hline Porosity (\%) & 22.05 & 10 & 17.46 & $\mathrm{mD}$ \\
Permeability (mD) & 50 & 0.02 & 1.9 & $\mu \mathrm{m}$ \\
R50 - Median pore access radius & 9.9 & 0. & 7.6 & $\mu \mathrm{m}$ \\
$\mathrm{R}_{\mathrm{a}}-$ Threshold pore access radius & 23 & 2.6 & 1 & \\
\hline
\end{tabular}

(***) Ballas (2013); Ballas et al., (2014).

\section{S4 Formation waters $\left(\delta^{18} \mathrm{O}_{\text {fluid }}\right)$ composition}

95 Oxygen isotope composition in minerals $\left(\delta^{18} \mathrm{O}_{\text {carb }}\right)$ are not a direct measurement of the $\delta^{18} \mathrm{O}$ composition of the formation waters $\left(\delta^{18} \mathrm{O}_{\text {fluid }}\right)$ at the time of cement precipitation, since the oxygen isotopic fractionation between water and calcite depends on temperature (e.g. Friedman \& O’Neil, 1977). To this end, we adopted the fractionation formula of Friedman and O'Neil (1977) for water-calcite system, assuming $10{ }^{\circ} \mathrm{C}$ as the temperature of superficial fluids, 200-500 $\mathrm{m}$ as the depth range, and a geothermal gradient of $20{ }^{\circ} \mathrm{C} / \mathrm{km}$ for Loiano. We did the same for Bollène, assuming $400 \mathrm{~m}$ as the maximum

100 burial depth (Ballas et al., 2013; Soliva et al., 2013). A temperature range of $14-20{ }^{\circ} \mathrm{C}$ for Loiano and $18{ }^{\circ} \mathrm{C}$ for Bollène has 
been estimated, respectively. The depth range for nodule formation in Loiano has been assumed considering that if the nodules are due to meteoric water infiltration, then the flow lines would have travelled, at most, a maximum distance from the ridges that delimit the valleys until the contact with the Liguride units (regional seal; e.g. Monghidoro Fm.), thus, at a maximum depth of 400-500 m. Results of the back-calculation of the $\delta^{18} \mathrm{O}$ composition of the cementing fluids are reported in Tables S4.1 and S.4.2 for Loiano and Bollène samples, respectively.

Table S4.1 Isotopic composition of cementing fluids at Loiano

\begin{tabular}{lcc}
\hline Feature & \multicolumn{1}{c}{$\boldsymbol{\delta}^{\mathbf{1 8}} \mathbf{O}_{\text {fluid }}(\mathbf{\%} \mathbf{V - S M O W})$ at $14{ }^{\circ} \mathrm{C}$} \\
\hline DBs-parallel nodules & Min; Max & Mean \\
\hline Bedding-parallel nodules & $-5.42 ;-2.31$ & -3.73 \\
\hline Feature & $-3.03 ;-2.26$ & -2.75 \\
\hline & $\boldsymbol{\delta}^{\mathbf{1 8}} \mathbf{O}_{\text {fluid }}\left(\mathbf{\%} \mathbf{V}\right.$-SMOW) at $20{ }^{\circ} \mathrm{C}$ \\
\hline DBs-parallel nodules & Min; Max & Mean \\
Bedding-parallel nodules & $-4.01 ;-0.90$ & -2.33 \\
\hline
\end{tabular}

Table S4.2 Isotopic composition of cementing fluids at Bollène

\begin{tabular}{lcc}
\hline Feature & \multicolumn{2}{c}{$\boldsymbol{\delta}^{\mathbf{1 8}} \mathbf{O}_{\text {fluid }}(\mathbf{\% o}$ V-SMOW) } \\
\hline & Min; Max & Mean \\
\hline DBs-parallel nodules & $-7.85 ;-5.98$ & -7.19 \\
Calcrete & $-6.70 ;-6.44$ & -6.62 \\
\hline
\end{tabular}

\section{References}

Antonellini, M. and Mollema, P.: Cataclastic faults in the Loiano sandstones; northern Apennines, Italy, Boll. Soc. Geol. Ital. 121(2), 163-178, 2002.

115 Ballas, G.: Modèle structural, mécanique et pétrophysique de la localisation de la déformation dans les grès Poreux

(Provence, France). Sciences de la Terre. Université Montpellier II - Sciences et Techniques du Languedoc. Français. https://tel.archives-ouvertes.fr/tel-01001389, 2013.

Cibin, U., Spadafora, E., Zuffa, G.G., and Castellarin, A.: Continental collision history from arenites of episutural basins in the Northern Apennines, Italy, Geol. Soc. Am. Bull. 113 (1), 4-19, https://doi.org/10.1130/00167606(2001)113<0004:CCHFAO>2.0.CO;2, 2001.

Friedman, I., and O’Neil, J.R., 1977, Compilation of stable isotope fractionation factors of geochemical interest: U.S. Geological Survey Professional Paper 440-KK, p. 1-117, https://doi.org/10.3133/pp440KK. 
Lacombe, O., and Jolivet, L.: Structural and kinematic relationships between Corsica and the Pyrenees-Provence domain at the time of the Pyrenean orogeny, Tectonics, 24(1), https://doi.org/10.1029/2004TC001673, 2005.

125 Saillet, E.: La localisation de la déformation dans les grès poreux: caractérisation d'un analogue de réservoir gréseux et faillé dans le Bassin du Sud-Est, Provence, France. Unpublished Docteur en Sciences thesis, Université de NiceSophia Antipolis, 2009.

Sanchis, E. and Séranne, M.: Structural style and tectonic evolution of a polyphase extensional basin of the Gulf of Lion passive margin: the Tertiary Alès basin, southern France. Tectonophysics 322, 219-242, https://doi.org/10.1016/S0040-1951(00)00097-4, 2000. 